\title{
Spontaneous Recovery After Extinction of the Conditioned Proboscis Extension Response in the Honeybee
}

\author{
Jean-Christophe Sandoz ${ }^{1,3}$ and Minh-Hà Pham-Delègue ${ }^{2}$ \\ ${ }^{1}$ Centre de Recherches sur la Cognition Animale, CNRS UMR 5169, Université Paul Sabatier, 31062 Toulouse cedex 04, France; \\ ${ }^{2}$ Laboratoire de Neurobiologie Comparée des Invertébrés, INRA, 91440 Bures-sur-Yvette, France
}

\begin{abstract}
In honeybees, the proboscis extension response (PER) can be conditioned by associating an odor stimulus (CS) to a sucrose reward (US). Conditioned responses to the CS, which are acquired by most bees after a single CS-US pairing, disappear after repeated unrewarded presentations of the CS, a process called extinction. Extinction is usually thought to be based either on (1) the disruption of the stored CS-US association, or (2) the formation of an inhibitory "CS-no US" association that is better retrieved than the initial CS-US association. The observation of spontaneous recovery, i.e., the reappearance of responses to the CS after time passes following extinction, is traditionally interpreted as a proof for the formation of a transient inhibitory association. To provide a better understanding of extinction in honeybees, we examined whether time intervals during training and extinction or the number of conditioning and extinction trials have an effect on the occurrence of spontaneous recovery. We found that spontaneous recovery mostly occurs when conditioning and testing took place in a massed fashion (1-min intertrial intervals). Moreover, spontaneous recovery depended on the time elapsed since extinction, $1 \mathrm{~h}$ being an optimum. Increasing the number of conditioning trials improved the spontaneous recovery level, whereas increasing the number of extinction trials reduced it. Lastly, we show that after single-trial conditioning, spontaneous recovery appears only once after extinction. These elements suggest that in honeybees extinction of the PER actually reflects the impairment of the CS-US association, but that depending on training parameters different memory substrates are affected.
\end{abstract}

A general property of associative learning phenomena is that acquired conditioned responses are extinguished by presenting the CS without the US (e.g., Pavlov 1927). In several animal preparations, extinction of conditioned responses after unreinforced CS presentations is not definitive because responses were found to recover after some time (Robbins 1990; Rosas and Bouton 1996; Rescorla 1997a, 2001). Spontaneous recovery is the return of conditioned responses elicited by the CS after time passes following extinction, and is usually interpreted as the indication that during extinction, a transient inhibitory association superimposed on the CS-US association decreases conditioned responses without destroying the initial CS-US association. The study of spontaneous recovery is thus particularly important in the understanding of associative learning and memory, because it can tell us how much of the CS-US association is preserved through extinction (Rescorla 1996, 1997a).

Honeybees (Apis mellifera L.) can be trained to associate an odor CS with a sucrose US, by conditioning the proboscis extension response (PER; Kuwabara 1957; Vareschi 1971; Bitterman et al. 1983). When the antennae of a hungry bee are touched with sucrose solution, the animal reflexively extends its proboscis to suck the sucrose. Odors to the antennae do not usually release such a response in naive animals. If an odor is presented immediately before sucrose solution (forward pairing), an association is

\section{${ }^{3}$ Corresponding author.}

E-MAIL sandoz@cict.fr; FAX 33-561-55-61-54.

Article and publication are at http://www.learnmem.org/cgi/doi/10.1101/ Im.81504. formed and the odor will subsequently release the PER in a following test. This effect is clearly associative and involves classical conditioning (Bitterman et al. 1983). Thus, the odor can be viewed as the conditioned stimulus (CS) and sucrose solution as the reinforcing unconditioned stimulus (US). In this paradigm, high response levels are obtained already after a single conditioning trial, which allowed dissecting the time- and eventdependency of the olfactory memory. Thus, at least five memory stages were described, which control performance within different time windows and are thought to depend on different neural substrates (different cells and/or molecular cascades) possibly in different brain structures (Menzel 1999, 2001).

After a single conditioning trial, performance in response to the CS is high shortly (1-2 min) after conditioning, then decreases, showing a "dip" around $3 \mathrm{~min}$, and is high again after 7 min, until about $1 \mathrm{~d}$, when performance decays (Fig. 1A). Two memory stages are thought to take place: in the first minutes after conditioning, performance depends on short-term memory (STM), which is highly nonassociative (because of sensitization from the US). STM decays quickly, i.e., within the first 2 to $3 \mathrm{~min}$. In that time, a consolidation process has started, which leads to the highly odor-specific midterm memory (MTM), which lasts $\sim 1$ $\mathrm{d}$. This consolidation is characterized by a prolonged activity of the cAMP-dependent protein kinase (PKA; Müller 2000).

After multiple conditioning trials, performance can be very high for several days or even several weeks (Fig. 1B). Four different memory forms, which are organized either sequentially or in parallel and can depend on different substrates from after singletrial conditioning, are formed. After an initial STM phase (which 
A

Performance after single-trial conditioning

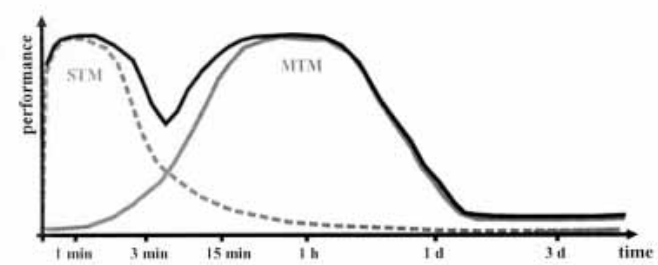

B

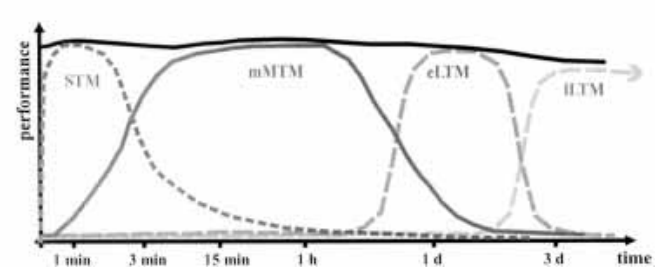

Figure 1 Model of olfactory memory phases in the honeybee (after Menzel 2001). The graphs (black lines) show the time course of performance after single-trial $(A)$ or multiple-trial $(B)$ PER conditioning. Gray lines indicate the different putative memory phases supporting performance at different times after conditioning. $(A)$ After a single conditioning trial, the olfactory memory is thought to go through mainly two phases, an initial (highly nonassociative) short-term memory phase (STM, broken gray line), and a later appearing midterm memory (single-trial MTM, gray line), which disappears normally after $\sim 1 \mathrm{~d}$. The transition between the two phases usually leads to a performance "dip" $\sim 3$ min after conditioning. (B) Multiple conditioning trials induce high performance for several days (black line). After an initial short-term memory phase, memory consolidate into another, more resistant, midterm memory storage (multiple-trial MTM) and, in time, to two forms a longterm memory, one independent of protein synthesis (early LTM), the other critically depending on the synthesis of new proteins (late LTM).

may include two forms, early and late STM), consolidation leads to an MTM phase (multiple-trial MTM) that is characterized by a selective increase in $\mathrm{Ca}^{2+} /$ calmodulin-dependent protein kinase C (PKC) activity (Grünbaum and Müller 1998). As before, multiple-trial MTM decays in the range of $1 \mathrm{~d}$. In the day's range, performance is controlled by two parallel Long-Term Memory (LTM) phases. One early phase (eLTM) is protein-synthesisindependent, and is predominantly induced by massed training (short intertrial intervals, usually $1 \mathrm{~min}$ ), whereas a late phase (ILTM) is critically dependent on protein synthesis and is only formed after spaced training (long intertrial intervals, usually 10 $\min )$. Therefore, depending on the number and the distribution of associative events, multiple memory forms are formed: short forms depending on short-term cellular modifications, later forms depending on the production of new proteins. In this, the memory system of honeybees is similar, although in different time windows, to that of other animal models, for instance, Drosophila (Heisenberg 2003) and vertebrates (Rose and Stewart 1999; Izquierdo et al. 2002).

In this context, one may ask whether extinction produces an additional inhibitory association superimposed on the existing CS-US association-and is thus independent of training variables-or if it actually provokes a decay of particular memory phases-in which case it should have a differential effect in different training conditions. One way to understand the effect of extinction on established memories is to study spontaneous recovery. In the former case, spontaneous recovery should be found independent of the number of conditioning trials and of the intervals between conditioning and extinction. In the latter case, different levels of spontaneous recovery should be observed in different training conditions. We addressed this question in the present work.

In honeybees, Takeda (1961) was the first to observe a phenomenon akin to spontaneous recovery. Training bees with 10 conditioning trials on one day, he subjected them to 23 unreinforced trials with the CS on a second day, and reached complete extinction. Takeda further presented the CS 32 times on a third day and on a fourth day. Some responding was obtained on the third day, indicating that responses could recover after extinction. Later on, Bitterman et al. (1983) trained bees with five conditioning trials and presented the CS unreinforced in 10 extinction trials with 1-min ITIs (massed trials) throughout the procedure, except for a 35-min rest period between the fifth and sixth trial. Although almost complete extinction was observed after five extinction trials, responses reached $70 \%$ again after the rest period, showing an important spontaneous recovery of conditioned responses. These two studies thus suggest that spontaneous recovery takes place in the honeybee. However, until now, no study has been dedicated to this phenomenon, although it is of primary importance in the elucidation of the mechanisms of learning and memory.

In the present work, we sought to reproduce spontaneous recovery in controlled laboratory conditions, and addressed the dependency of this phenomenon on the training variables. More precisely, we asked whether the time intervals during conditioning, extinction, or after extinction are important for the occurrence of spontaneous recovery. Moreover, we tested whether the number of conditioning and extinction trials of the procedure have an effect on the appearance and level of spontaneous recovery. Lastly, as it could further indicate whether extinction affects memory storage directly, we evaluated the possibility that spontaneous recovery occurs repeatedly after extinction. These data are interpreted with regard to the dynamics of the olfactory memory of honeybees.

\section{MATERIALS AND METHODS}

\section{Biological Material}

Emerging Italian worker bees (Apis mellifera ligustica) were collected on combs from outdoor hives and were caged in groups of $\sim 50-80$ individuals. They were kept in an incubator at $33^{\circ} \mathrm{C}, 55 \%$ $\mathrm{RH}$, with pollen, sugar, and water at will. Bees were used at the age of $14 \mathrm{~d}$ as workers usually become foragers at this age (Seeley 1982) and show good learning performances in the PER assay (Pham-Delègue et al. 1990). They were starved in the cage for $2 \mathrm{~h}$, and were then individually mounted in glass holders, with their mouthparts and antennae free. Experiments were performed $3 \mathrm{~h}$ later.

\section{Odor Stimulations}

For each odor stimulation, the bee was positioned in front of a $1-\mathrm{cm}$ diameter glass tube delivering a constant airflow $(52.5 \mathrm{~mL} /$ $\mathrm{sec})$. To familiarize bees to the mechanical stimulation of the flow, they were kept in the airflow for 15 sec before the odor was delivered. The airflow directed to the bee was composed of a main airflow $(50 \mathrm{~mL} / \mathrm{sec})$ added with a secondary airflow $(2.5$ $\mathrm{mL} / \mathrm{sec}$ ). This secondary airflow was directed using a low latency solenoid valve, either to a disposable Pasteur pipette containing a filter paper strip $(3 \times 40 \mathrm{~mm})$ soaked with $10 \mu \mathrm{L}$ of the odorant or to an identical empty pipette. A fan was set opposite to the airflow, behind the bee, to withdraw the released odors out of the experimental room. To facilitate the study of the extinction process, an odor CS that is easily learned by bees, i.e., which induces high performance levels, was required. All experiments 
were performed with pure linalool as the CS, because it gave a high and stable level of conditioned responses between $30 \mathrm{sec}$ and $3 \mathrm{~h}$ after only one CS-US association in previous work, responses after $24 \mathrm{~h}$ being slightly lower (Sandoz et al. 1995).

\section{Protocol}

About 30 min before the experiment started, the proboscis extension reflex of bees was tested by contacting their antennae with a $30 \%$ sucrose solution. Under our experimental conditions, $78 \%$ of bees showed a clear proboscis extension and were used in the experiments. This ensured high conditioning rates, even after one-trial conditioning (between 80\% and 100\%; see Results).

\section{Conditioning (Rewarded) Trials}

After $15 \mathrm{sec}$ of familiarization to the mechanical stimulation, the odor CS was presented to the bee for $6 \mathrm{sec}$. After $3 \mathrm{sec}$, the antennae were stimulated with a $30 \%$ sucrose solution (US) and the subsequent proboscis extension of the bee was rewarded by a food uptake (for $3 \mathrm{sec}$ ) with the same sucrose solution.

\section{Extinction (Unrewarded) Trials}

The bee was kept $15 \mathrm{sec}$ in the airflow, and the CS was delivered for $6 \mathrm{sec}$. The occurrence of a CR was noted, but no stimulation with the sugar solution was given.

\section{Experiment 1: Temporal Determinants of Spontaneous Recovery}

Because performance in PER conditioning depends on different memory phases depending on the time parameters of the training procedure (Menzel 1990, 1999; Menzel et al. 2001), we tested the dependency of the spontaneous recovery phenomenon on the time parameters of the acquisition and extinction procedure. We subjected three groups of bees to a procedure consisting of one conditioning trial, five extinction trials and of a last extinction trial at the end to check for spontaneous recovery (Table 1). Between groups, the time intervals between conditioning and extinction or between consecutive extinction trials varied. The interval between the conditioning trial and the beginning of the extinction procedure was either long $(10 \mathrm{~min})$ or short $(1 \mathrm{~min})$. Intervals between two consecutive extinction trials were likewise either long (15 min) or short (1 min). Within each group, three to four subgroups were made, according to the time during which the bees waited after the extinction phase and before we tested for spontaneous recovery. This period of time is later called "rest period," indicating that the bees did not receive any stimulation during that time. This rest duration was either the same interval as that used in the extinction procedure ( 1 or $15 \mathrm{~min}$, control rest interval) or was a longer period of time (rest intervals of $15 \mathrm{~min}, 1 \mathrm{~h}$, or $24 \mathrm{~h}$ ). Bees kept for the 24 -h tests were fed in the evening with a sugar solution different from the US $(25 \%$ fructose solution) and were kept in a dark and cool place overnight (Sandoz et al. 1995).

\section{Experiment 2: Effect of the Number of Conditioning and Extinction Trials on Spontaneous Recovery}

In this experiment, we asked whether the level of spontaneous recovery recorded after extinction depends on the number of rewarded (conditioning trials) or unrewarded (extinction trials) CS presentations. First, to evaluate the effect of the number of conditioning trials on the level of spontaneous recovery, we subjected four groups of bees to one, three, six, or nine conditioning trials and to five extinction trials (Table 1). All intertrial intervals were of $1 \mathrm{~min}$. The effect of spontaneous recovery was assessed in a last test trial performed $1 \mathrm{~h}$ after the last extinction trial. Second, to test the effect of the number of unrewarded trials of the extinction phase on spontaneous recovery, two groups of bees were subjected to a single conditioning trial, followed by either five or 10 extinction trials. All intervals between trials were of 1 min. Spontaneous recovery was evaluated in a test $1 \mathrm{~h}$ after the end of the extinction procedure.

\section{Experiment 3: Spontaneous Recovery and Retraining}

In this experiment, we evaluated whether the spontaneous recovery phenomenon is repeatable over time, i.e., if without new training, responses can be repeatedly extinguished and lead to spontaneous recovery. This would indicate that extinction, indeed, induces a transient negative association that does not affect the initial CS-US association. Moreover, we wanted to compare

Table 1. Experimental Design

\begin{tabular}{|c|c|c|c|c|c|}
\hline $\begin{array}{l}\text { Experimental } \\
\text { group }\end{array}$ & $\begin{array}{c}\text { Number of } \\
\text { conditioning trials }\end{array}$ & $\begin{array}{l}\text { Number of } \\
\text { extinction trials }\end{array}$ & $\begin{array}{l}\text { Time interval during } \\
\text { conditioning and between } \\
\text { conditioning and extinction }\end{array}$ & $\begin{array}{l}\text { Time interval } \\
\text { between } \\
\text { extinction trials }\end{array}$ & $\begin{array}{l}\text { Duration of } \\
\text { rest period }\end{array}$ \\
\hline \multicolumn{6}{|l|}{ Experiment 1} \\
\hline Long-long & 1 & 5 & $10 \mathrm{~min}$ & $15 \mathrm{~min}$ & $15 \mathrm{~mm}, 1 \mathrm{~h}, 24 \mathrm{~h}$ \\
\hline Long-short & 1 & 5 & $10 \mathrm{~min}$ & $1 \mathrm{~min}$ & $1 \mathrm{~min}, 15 \mathrm{~min}, 1 \mathrm{~h}, 24 \mathrm{~h}$ \\
\hline Short-short & 1 & 5 & $1 \mathrm{~min}$ & $1 \mathrm{~min}$ & $1 \mathrm{~min}, 15 \mathrm{~min}, 1 \mathrm{~h}, 24 \mathrm{~h}$ \\
\hline \multicolumn{6}{|l|}{ Experiment 2} \\
\hline 1-trial (Cond.) & 1 & 5 & $1 \mathrm{~min}$ & $1 \mathrm{~min}$ & $1 \mathrm{~h}$ \\
\hline 3-trial (Cond.) & 3 & 5 & $1 \mathrm{~min}$ & $1 \mathrm{~min}$ & $1 \mathrm{~h}$ \\
\hline 6-trial (Cond.) & 6 & 5 & $1 \mathrm{~min}$ & $1 \mathrm{~min}$ & $1 \mathrm{~h}$ \\
\hline 9-trial (Cond.) & 9 & 5 & $1 \mathrm{~min}$ & $1 \mathrm{~min}$ & $1 \mathrm{~h}$ \\
\hline 5-trial (Ext.) & 1 & 5 & $1 \mathrm{~min}$ & $1 \mathrm{~min}$ & $1 \mathrm{~h}$ \\
\hline 10-trial (Ext.) & 1 & 10 & $1 \mathrm{~min}$ & $1 \mathrm{~min}$ & $1 \mathrm{~h}$ \\
\hline \multicolumn{6}{|l|}{ Experiment $3^{a}$} \\
\hline Rest & 1 & 5 & $1 \mathrm{~min}$ & $1 \mathrm{~min}$ & $1 \mathrm{~h}$ \\
\hline Reminder & 1 & 5 & $1 \mathrm{~min}$ & $1 \mathrm{~min}$ & $1 \mathrm{~min}+$ conditioning trial \\
\hline Rest and reminder & 1 & 5 & $1 \mathrm{~min}$ & $1 \mathrm{~min}$ & $1 \mathrm{~h}+$ conditioning trial \\
\hline
\end{tabular}

an this experiment, four extinction phases are applied.

Experiment 1 evaluates the appearance of spontaneous recovery in different temporal conditions, with short or long intervals between trials after conditioning and in the extinction procedure. Experiment 2 evaluates the effect of the number of conditioning trials (Cond.) and of the number of extinction trials (Ext.) on spontaneous recovery, in fixed temporal conditions. Experiment 3 asks whether spontaneous recovery can appear several times after extinction, and compares the effect of spontaneous recovery with that of retraining (reminder trials). 
the effect of rest periods (passively allowing a response recovery: spontaneous recovery) to that of "reminder trials" (actively inducing a new response increase through retraining) after extinction. Bees were initially conditioned in a single trial and then subjected to four distinct extinction phases, each of five extinction trials, with 1-min intertrial intervals (Table 1 ). In the group Rest, a rest period of $1 \mathrm{~h}$ was given after each extinction phase. In the group Reminder, bees received a reminder trial (i.e., a new conditioning trial) after each extinction phase, but no rest interval. This new conditioning trial appeared thus $1 \mathrm{~min}$ after the last extinction trial. In the group Rest and reminder, bees received both treatments, first going through a 1 -h rest period and then receiving a conditioning trial, after each extinction phase.

\section{Statistics}

All our experiments consisted of three phases: acquisition, extinction, and recovery. In each case, the performances of bees over the whole procedure are shown in the figures. However, because the critical test was that for recovery at the end of the procedure, we had to ensure that all groups showed similar conditioning and extinction performances before carrying out statistical tests for recovery.

First, we compared between groups the level of responses reached after conditioning, i.e., at the first extinction trial. This was done using a $\chi^{2}$ test. If responses after conditioning were found to be statistically heterogeneous, we only kept for further analysis the bees that were efficiently conditioned, i.e., which responded at the first extinction test. This was to ensure that only conditioned bees would be afterward compared for extinction and spontaneous recovery. This only happened in Experiment 2, in which bees received different numbers of conditioning trials.

Second, we compared between groups the level of responses shown by bees after extinction, i.e., at the last extinction trial, using a $\chi^{2}$ test. As before, in Experiment 2, a significant heterogeneity was found in responses after extinction. In this case, we analyzed only absolute spontaneous recovery data, i.e., only response recovery from bees that had extinguished, again to compare the different groups in similar conditions (see below).

Lastly, we tested spontaneous recovery. Within each group, we applied a McNemar test to check whether responding after the rest period was statistically higher than before. Groups that

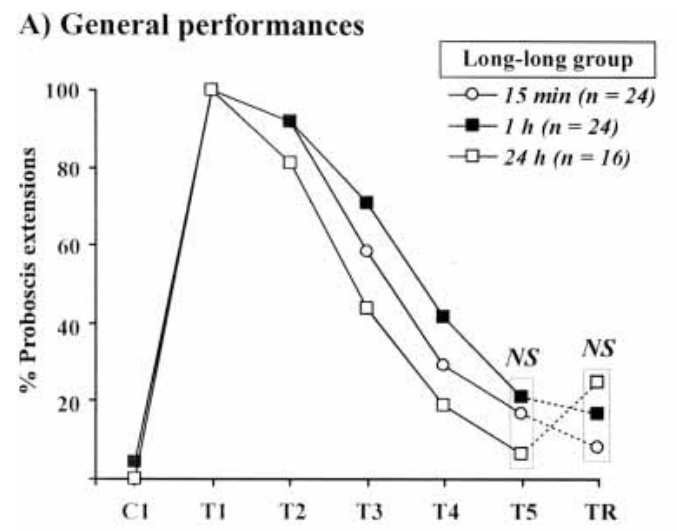

B) Recovery
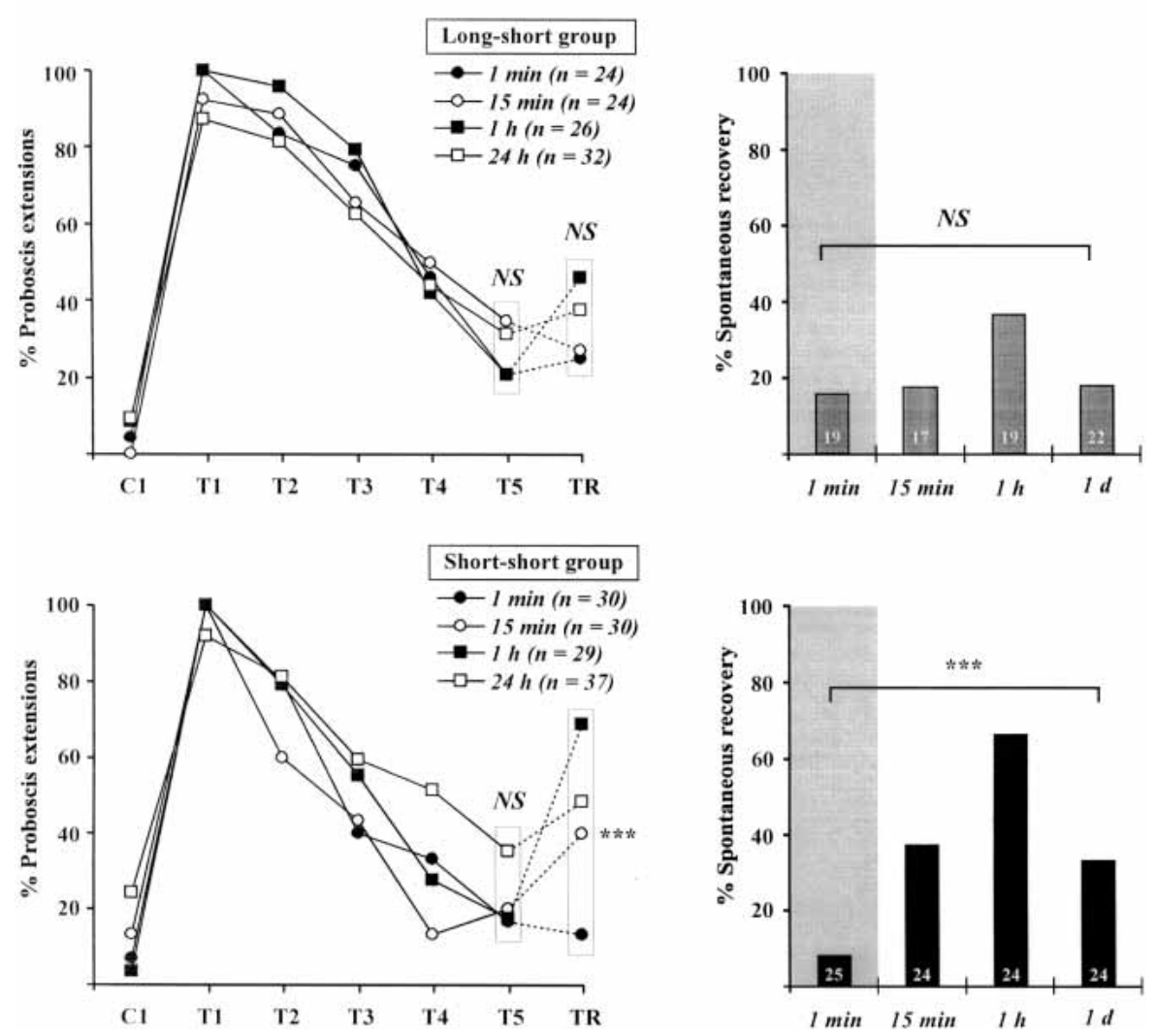

Figure 2 Temporal determinants of spontaneous recovery. Spontaneous recovery was evaluated according to the duration of intervals during conditioning and extinction and of the rest period after extinction. All groups received one conditioning trial, five extinction trials, and one recovery trial (Table 1). Intervals between conditioning and extinction were of $10 \mathrm{~min}, 10 \mathrm{~min}$, and $1 \mathrm{~min}$; intertrial intervals in the extinction procedure were of $15 \mathrm{~min}, 1 \mathrm{~min}$, and $1 \mathrm{~min}$, respectively, for groups Long-long (upper panel), Long-short (middle panel), and Short-short (lower panel), respectively. In each group, subgroups represent different rest periods after extinction, either 1 min (only for the last two groups), $15 \mathrm{~min}, 1 \mathrm{~h}$, or $24 \mathrm{~h}$. (A) overall performances of honeybees. (B) Absolute recovery, i.e., proportion of bees not responding at the end of the extinction procedure (see numbers) that responded at the recovery test. When intertrial intervals were long, almost no spontaneous recovery was observed (group Long-long). When extinction began late after conditioning but was carried out in a massed schedule (group Long-short), little spontaneous recovery appeared, except for a tendency with a rest period of $1 \mathrm{~h}$. In contrast, when the whole procedure was carried out in a massed fashion, high spontaneous recovery was observed (group Short-short). It increased with the duration of the rest period after extinction until $1 \mathrm{~h}$. After $1 \mathrm{~d}$, spontaneous recovery was lower. Significance is shown for responses at individual trials during conditioning, extinction, or at the recovery test $\left[x^{2}\right.$ test with 2 or $\left.3 \mathrm{df} ;{ }^{* * *}\right) p<0.001$; (NS) nonsignificant]. showed a significant outcome in this test were considered as having shown spontaneous recovery. We considered as "absolute recovery" the proportion of bees that did not respond at the 
last extinction trial but responded at the recovery test. We compared between groups the level of absolute recovery using $\chi^{2}$ tests.

\section{RESULTS}

\section{Experiment 1: Temporal Determinants of Spontaneous Recovery}

Figure $2 \mathrm{~A}$ presents the overall performances of three groups of bees subjected to one conditioning trial, five extinction trials, and a recovery test, and Figure $2 \mathrm{~B}$ presents the absolute recovery data.

In the Long-long group (Fig. 2A, upper panel), all bees learned to respond to linalool after one CS-US association $(n=16-24)$. During repeated unrewarded CS presentations, responses decreased to a level of $6 \%-21 \%$ at the fifth extinction test without any heterogeneity among subgroups $\left(\chi^{2}\right.$ test, $\chi^{2}=1.6$, $\mathrm{NS}, 2 \mathrm{df})$. After a rest period between $15 \mathrm{~min}$ and $24 \mathrm{~h}$, responses in the recovery test (TR) ranged from $8 \%$ to $25 \%$, without any significant difference among subgroups $\left(\chi^{2}\right.$ test, $\chi^{2}=2.1$, NS, 2 df). McNemar tests comparing responses before and after the rest period yielded only nonsignificant outcomes (McNemar test, $\chi^{2}<1.3$, NS). When observing the absolute recovery percentage (i.e., bees that had extinguished at the end of extinction and that responded to the recovery test), responses ranged from $0 \%$ to $21 \%$ $(n=15-20)$ and no difference appeared among subgroups $\left(\chi^{2}\right.$ test, $\chi^{2}=5.2$, NS, 2 df). Therefore, when the intervals of the conditioning and extinction procedure were long, no significant spontaneous recovery of conditioned responses was found after extinction.

In the Long-short group (Fig. 2A, middle panel), bees showed between $88 \%$ and $100 \%$ conditioned responses after one CS-US trial $(n=24-32)$. Responses then decreased with unrewarded CS presentations to a level of $21 \%-35 \%$ responses at the fifth extinction trial, without any difference among groups ( $\chi^{2}$ test, $\chi^{2}=2.0$, NS, $\left.3 \mathrm{df}\right)$. After a rest period between $1 \mathrm{~min}$ and $24 \mathrm{~h}$, responses in the recovery test ranged from $25 \%$ to $46 \%$, without any difference among groups $\left(\chi^{2}\right.$ test, $\chi^{2}=3.1$, NS, 3 df). For a rest period of $1 \mathrm{~h}$, responses increased from $21 \%$ to $46 \%$ over the rest period, which was near-significant (McNemar test, $\left.\chi^{2}=3.2, p=0.07\right)$. Comparisons for other durations yielded strictly nonsignificant outcomes (McNemar test, $\chi^{2}<1.3$, NS). Absolute recovery ranged from $16 \%$ to $37 \%$, with a tendency for higher recovery in the 1-h subgroup, but overall comparison among groups gave a nonsignificant outcome $\left(\chi^{2}\right.$ test, $\chi^{2}=3.2$, NS, $3 \mathrm{df}$ ). Therefore, when the interval after conditioning was long but the intervals during extinction were short, only a tendency (but no significant effect) for spontaneous recovery of conditioned responses was found after extinction. nonsignificant].
In the Short-short group (Fig. 2A, lower panel), bees showed between $92 \%$ and 100\% conditioned responses after one CS-US association $(n=29-37)$. Responses then decreased with unrewarded CS presentations to a level of $17 \%-35 \%$ responses at the fifth extinction trial, without significant heterogeneity among groups ( $\chi^{2}$ test, $\chi^{2}=4.4, \mathrm{NS}, 3 \mathrm{df}$ ). After a rest period, responses in the recovery test were highly heterogeneous, ranging from 13\% for a $1-$ min rest period to $69 \%$ for the 1 -h rest period $\left(\chi^{2}\right.$ test, $\left.\chi^{2}=19.3, p<0.001,3 \mathrm{df}\right)$. In particular, for a rest period of $1 \mathrm{~h}$, responses increased from $17 \%$ to $69 \%$ over the rest period, which was highly significant (McNemar test, $\chi^{2}=11.5, p<0.001$ ). Comparisons for other durations yielded only nonsignificant outcomes (McNemar test, $\chi^{2}<2.1$, NS). Overall comparison of absolute recovery in the different subgroups showed a highly significant outcome (Fig. 2B, lower panel; $\chi^{2}$ test, $\chi^{2}=18.4, p<0.001,3$ df). Direct comparison of recovery after rest periods of $15 \mathrm{~min}$ $(38 \%), 1 \mathrm{~h}(67 \%)$, and $24 \mathrm{~h}(33 \%)$ with recovery after $1 \mathrm{~min}(8 \%$, our reference because it was the interval between extinction trials) yielded in all cases a significant outcome (Fisher's exact test; $p=0.018, p<0.001$, and $p=0.037$, respectively; $1 \mathrm{df})$. Therefore, when the intervals after conditioning and during extinction were short, significant spontaneous recovery of conditioned responses was observed, which depended on the rest period given to bees
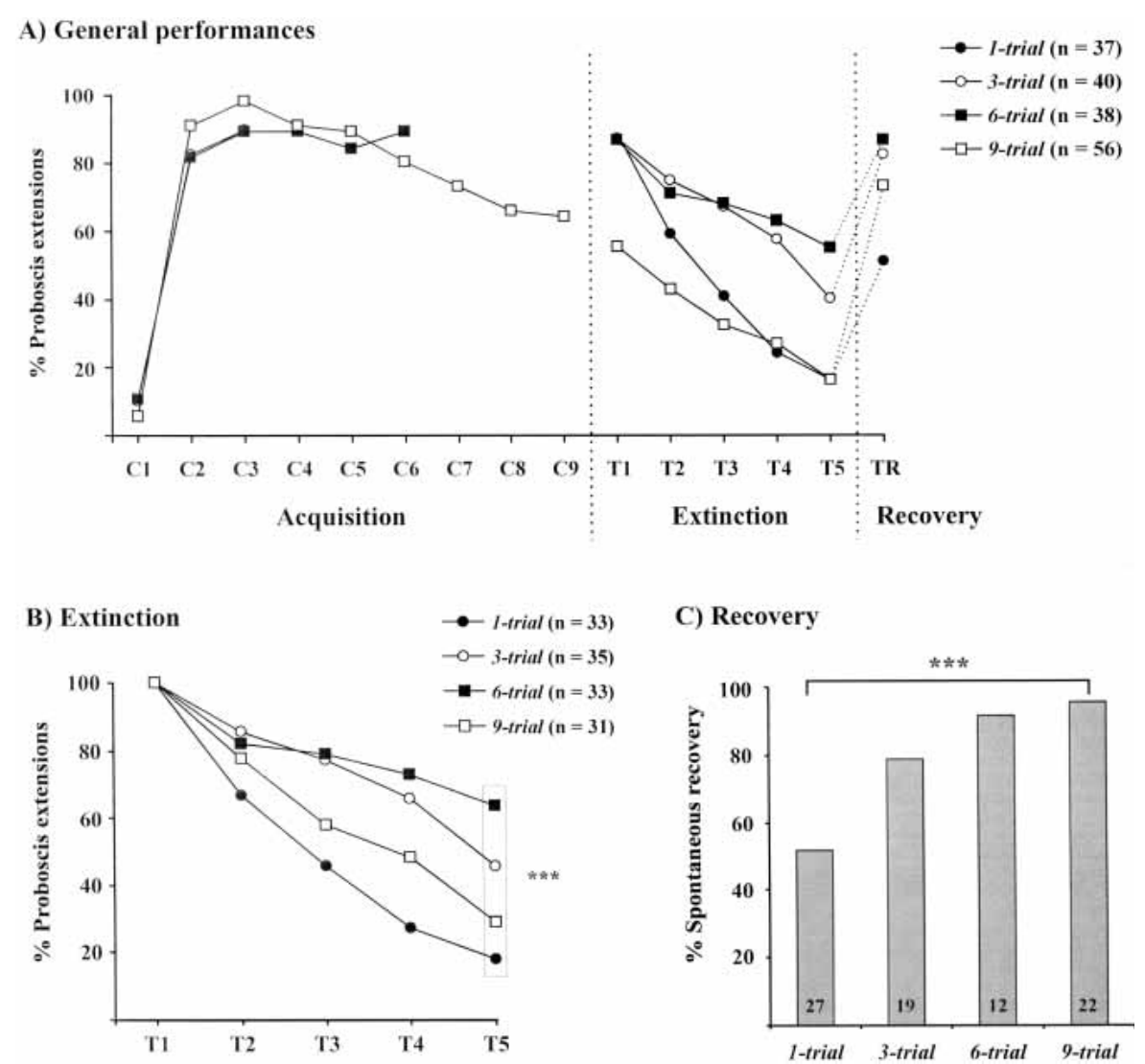

Figure 3 Effect of the number of conditioning trials on spontaneous recovery. Bees received one, three, six, or nine conditioning trials, and were then subjected to five extinction trials and to a recovery test after a 1-h rest period. $(A)$ Overall performances. Because bees showed heterogeneous levels of responses at the end of training, $(B)$ shows extinction in bees responding at the first extinction test. This effect of the number of conditioning trials on extinction was nonmonotonous, resistance to extinction increasing from one-trial to six-trial conditioning, but decreasing for nine-trial conditioning. $(C) A b-$ solute recovery data are shown as proportion of bees not responding at the end of the extinction procedure (see numbers) that responded at the recovery test. Spontaneous recovery was higher after multiple conditioning trials than after a single trial. Significance is shown for responses at individual trials during conditioning, extinction, or at the recovery test $\left[\chi^{2}\right.$ test with $\left.3 \mathrm{df} ;{ }^{* * *}\right) p<0.001$; (NS) 


\section{A) General performances}

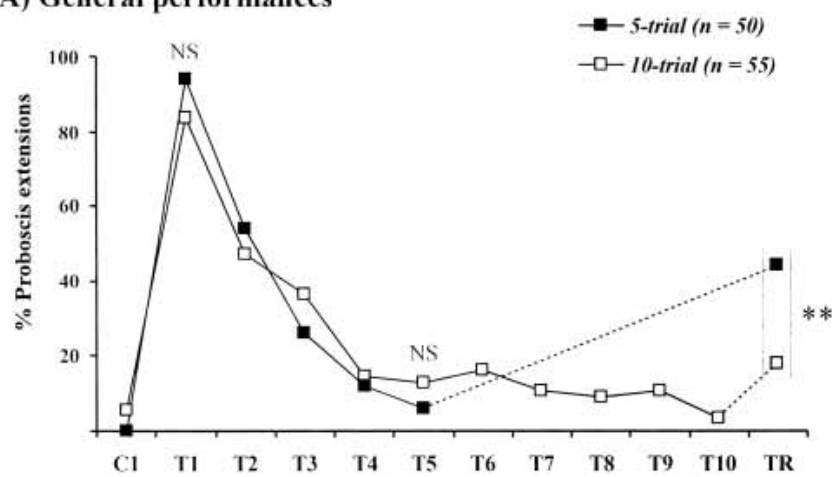

Figure 4 Effect of the number of extinction trials on spontaneous recovery. Bees received one conditioning trial and were then subjected to either five or 10 extinction trials and to a recovery test after a 1-h rest period. (A) Overall performances. Performances during conditioning and extinction were similar in the two groups, responses at the end of extinction (either five or 10 extinction trials) being below $16 \%$. (B) Absolute recovery. Data are shown as the proportion of bees not responding at the end of the extinction procedure (see numbers) that responded at the recovery test. Recovery was higher after five than after 10 extinction trials. Significance is shown for responses at individual trials during conditioning, extinction, or at the recovery test $\left[\chi^{2}\right.$ test with $1 \mathrm{df} ;\left(^{*}\right) p<0.05 ;\left({ }^{* *}\right) p<0.01$; (NS) nonsignificant].

after extinction. This experiment shows that the occurrence of spontaneous recovery is highly dependent on the interval between conditioning and extinction, on the intertrial interval of the extinction procedure, and on the rest period. Maximal spontaneous recovery was obtained for conditioning and extinction intervals of $1 \mathrm{~min}$ and for a rest period of $1 \mathrm{~h}$. These conditions were therefore used in all other experiments.

\section{Experiment 2: Effect of the Number of Conditioning and Test Trials on Spontaneous Recovery}

\section{Number of Conditioning Trials}

When conditioning bees with a different number of conditioning trials in a massed schedule (1-min intertrial intervals), acquisition was very rapid, all groups responding with $>81 \%$ at the second odor presentation (Fig. 3A). The response level remained high from one to six conditioning trials $(>80 \%)$, but tended to decrease in the group conditioned in nine trials (down to 64\%). Comparing the performance of the different groups, we never found any significant difference until after the sixth trial (comparison between the one-trial, three-trial, six-trial, and nine-trial groups after the first trial: $\chi^{2}$ test, $\chi^{2}=2.57,3 \mathrm{df}$, NS; between the three-trial, six-trial, and nine-trial groups after the third trial: $\chi^{2}=0.31,2 \mathrm{df}, \mathrm{NS}$; between the six-trial and the nine-trial groups after the sixth trial: $\chi^{2}=2.51,1 \mathrm{df}, \mathrm{NS}$ ). However, responses at the first extinction trial were heterogeneous, ranging between $55 \%$ and $89 \%\left(\chi^{2}\right.$ test, $\left.\chi^{2}=22.6, p<0.001,3 \mathrm{df}\right)$. Therefore, extinction data were analyzed only on bees that responded at the first extinction test (Fig. 3B; in this figure, because bees were selected, all groups show $100 \%$ responses at the first extinction trial). Extinction was also very different depending on the number of conditioning trials ( $\chi^{2}$ test, $\chi^{2}=16.3, p<0.001,3 \mathrm{df}$ ). Conditioned responses resisted very little for one-trial conditioning, decreasing to $18 \%$, but increasing resistance to extinction was found with increasing numbers of conditioning trials (up to 63\% responses at the end of extinction for six-trial conditioning). However, resistance to extinction decreased again for nine-trial conditioning (29\% responses at the end of extinction). Such a bellshaped relationship between extinction and the number of conditioning trials is reminiscent of an overlearning extinction

B) Recovery

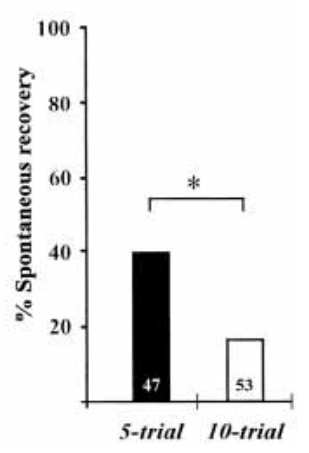

effect, but may also be caused by different satiation levels. Owing to the heterogeneity in the outcome of extinction, only absolute recovery data were analyzed in this group (Fig. 3C). Responses at the recovery test increased between $52 \%$ in the 1 -trial group to $79 \%$ in the 3 -trial group, and remained at a high level in the 6-trial and the 9-trial groups (89\% and $92 \% ; n=12-27)$. A significant heterogeneity appeared among groups $\left(\chi^{2}=15.0, p<0.01,3 \mathrm{df}\right)$. Thus, an increase in the number of conditioning trials significantly increased the spontaneous recovery level.

\section{Number of Extinction Trials}

In both experimental groups, one-trial conditioning was equally efficient (Fig. $4 \mathrm{~A}$ ), inducing $83 \%-94 \%$ responses, respectively, at the first extinction trial $\left(\chi^{2}\right.$ test, $\chi^{2}=2.8$, NS, $1 \mathrm{df}$ ). In the extinction phase, responses decreased in both groups to $6 \%$ and $15.2 \%$ at the fifth extinction trial, without any difference between groups ( $\chi^{2}$ test, $\left.\chi^{2}=1.3, \mathrm{NS}, 1 \mathrm{df}\right)$. In the 10-trial group, responses remained very low thereafter (below 10\%) and were of $3.6 \%$ at the last trial. No difference appeared between responses in the last extinction trial of each group (fifth trial vs. tenth trial, $\chi^{2}$ test, $\chi^{2}=0.3$, NS, $1 \mathrm{df}$ ). After a 1 -h rest period, responses reached $44 \%$ after a five-trial extinction procedure and $18 \%$ after a 10-trial extinction procedure. In both cases, a significant spontaneous recovery was obtained, responses after the rest period being significantly higher than at the last extinction trial (5-trial group: Mc Nemar test, $\chi^{2}=15.4, p<0.001 ; 10$-trial group, McNemar test, $\left.\chi^{2}=4.9, p<0.05\right)$. The comparison of spontaneous recovery in the two groups was significant, both on the overall data ( $\chi^{2}$ test, $\chi^{2}=8.2, p<0.01,1 \mathrm{df}$ ), and on bees not responding at the last extinction trial (absolute recovery, Fig. 4B; $\chi^{2}$ test, $\left.\chi^{2}=7.9, p<0.01 ; 1 \mathrm{df}\right)$. Therefore, an increase in the number of extinction trials, even though extinction was already attained after five trials, significantly reduced spontaneous recovery.

\section{Experiment 3: Spontaneous Recovery and Retraining}

In the three groups, most bees learned the CS in one trial, responding with 93.3\% $(n=30), 90.3 \%(n=31)$, and $82.3 \%$ $(n=34)$ at the first extinction trial in the groups Rest, Reminder, and Rest and reminder, respectively ( $\chi^{2}$ test, $\chi^{2}=2.7$, NS, $\left.2 \mathrm{df}\right)$. As during the experimental procedure, two groups of bees received Reminder trials, which are supposed to recall a previously learned association, only those bees that showed successful learning after initial conditioning were kept for further analysis $(n=28$ in each group). The percentages of responses obtained for the three groups during the 20 testing trials of the four extinction phases are presented in Figure 5. The extinction rates obtained at the fifth testing trial were similar in the three groups, with $10.7 \%$, $3.6 \%$, and $7.1 \%$ responses, respectively, in the groups Rest, Reminder, and Rest and reminder ( $\chi^{2}$ test, $\chi^{2}=1.07, \mathrm{NS}, 2 \mathrm{df}$ ).

When a resting period was applied after each extinction phase (group Rest; $n=28$ ), spontaneous recovery was observed only after the first extinction phase. In trial 6, responses reached $57.1 \%$, which was significantly higher than responses in trial 5 (McNemar test, $\chi^{2}=11.1, p<0.001$ ). After the second extinction phase (T6 to T10), the increase produced by the 1-h rest period reached only $21.4 \%$, which was not statistically different from 

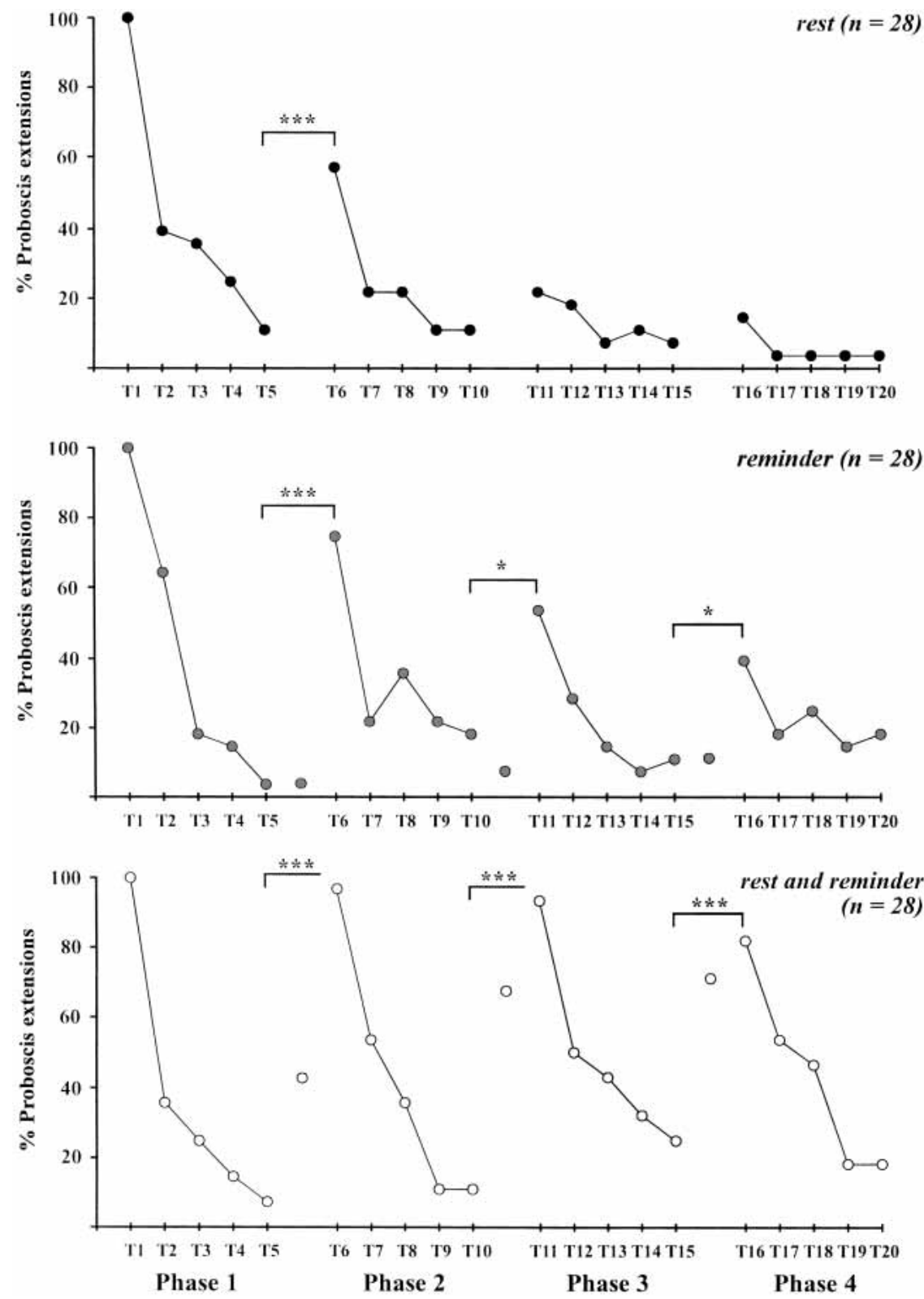

Figure 5 Spontaneous recovery and retraining. Bees received one conditioning trial and were subjected to four phases of five extinction trials (T1 to T20). Different treatments were applied between two phases. In the group Rest (upper panel), bees received a rest period of $1 \mathrm{~h}$. Bees of the group Reminder (middle panel) received a conditioning trial. In the group Rest and reminder (lower panel), bees received first a 1 -h rest period, then a conditioning trial. Spontaneous recovery (after a 1-h rest period) appeared only once along the successive extinction phases (Rest), whereas responses reappeared after each recall trial (Reminder). After each application of a rest period and a recall trial, responses reappeared at the maximal level (Rest and reminder). Significance is shown in each group between responses at the end of an extinction phase and the beginning of the next one [McNemar test, $1 \mathrm{df} ;\left(^{*}\right) p<0.05 ;\left(^{* * *}\right) p<0.001$; (NS) nonsignificant].

the responses at trial 10 (McNemar test, $\chi^{2}=1.3$, NS; $\left.1 \mathrm{df}\right)$. Responses remained thereafter very low, without any recovery after the third rest period.

When reminder trials were applied after each extinction phase (group Reminder, $n=28$ ), a novel increase in responses was obtained after each reminder trial. However, the response level decreased throughout the extinction-reminder series $(75 \%$, $53.6 \%$, and $39.3 \%$ after the first, second, and third extinction phases, respectively). The response level after reminder was in all cases significant but with decreasing levels (McNemar test, $\chi^{2}=18.0, p<0.001$ after the first reminder trial; $\chi^{2}=5.8, p<0.05$ after the second; and $\chi^{2}=4.9, p<0.05$ after the third). Each reminder trial was performed $1 \mathrm{~min}$ after the last extinction trial, and as expected no spontaneous recovery of responses occurred, responses at the beginning of this trial (i.e., before the US was given) amounting to $4 \%, 7 \%$, and $11 \%$, respectively, at the first, second, and third reminder trial (see lone points in Fig. 5, middle panel). This proportion was in all cases nonsignificant in comparison to the last extinction trial (McNemar test, $\chi^{2}<0.8$, NS).

Lastly, when both a rest period and a reminder trial were applied (group Rest and reminder, $n=28$ ), a high maintenance of the response levels was observed throughout the four phases, bees showing 96.4\%, $92.8 \%$, and $82.1 \%$ responses after the first, second, and third Rest and reminder treatments, respectively (i.e., in trials T6, T11, and T16). In all cases, this recovery of responses was highly significant (McNemar test, $\chi^{2}>14.1, p<0.001$ for all comparisons between the last trial of an extinction series and the first of the next series). Interestingly, because each reminder trial was performed after a 1-h rest period, we could measure the level of spontaneous recovery obtained after each rest period (see lone points in Fig. 5, lower panel). Bees thus responded with $43 \%, 68 \%$, and $71 \%$, respectively, at the first, second, and third reminder trials, which was in all cases significant in comparison to the last extinction trial (McNemar test, $\chi^{2}>8.1, p<0.01$ ); thus spontaneous recovery occurred in each case.

\section{DISCUSSION}

We show that: (1) Extinction of conditioned PER is not always definitive and spontaneous recovery of responses can occur. (2) Spontaneous recovery is highly dependent on time intervals during acquisition and extinction. Massed procedures are more likely to produce spontaneous recovery than spaced ones. (3) Multiple conditioning trials increase the amount of spontaneous recovery, whereas extended extinction diminishes it. (4) Spontaneous recovery can only appear once after extinction, whereas reminder trialsapplied with or without rest periods-allow maintaining the response level throughout several extinction phases.

\section{Could Spontaneous Recovery Be Due to Nonassociative Effects?}

Because bees received sucrose solution (US) during conditioning trials, we may ask whether the increase in responding observed after time passed after extinction could be due to a nonassocia-

\section{Learning \& Memory}

www.learnmem.org 
tive effect like sensitization, or even hunger, developing since the last sucrose reward. Sensitization is the unspecific enhancement of response probability to a stimulus (here the odor) caused by the preceding presentation of a strong stimulus (here the sucrose US). In the proboscis extension-conditioning paradigm, sensitization has been intensively studied (Brandes et al. 1988; Menzel 1990; Menzel et al. 1993; Hammer et al. 1994; Sandoz et al. 2002), and previous results as well as the present study show that it cannot account for the results found here. First, sensitization after sucrose stimulation was shown to be a very short-lived phenomenon, lasting typically 1 to 2 min after US presentation (Menzel 1990; Menzel et al. 1993; Sandoz et al. 2002), which corresponds to the STM phase. In our experiments, bees received a conditioning phase (usually a single trial), then were subjected to an extinction phase, and were then tested at different times with the CS. Thus, bees received only one US presentation, and significant spontaneous recovery was obtained $\sim 1 \mathrm{~h}$ and 5 min after this US presentation (Short-short group of Experiment 1, test after $1 \mathrm{~h}$, or identical groups in Experiment 2 and 3), at a time when sensitization is not active anymore. On the other hand, hunger could develop over time after the last feeding, and could also be a factor influencing bees' responses (Menzel et al. 1991; Friedrich et al. 2004). Again, this phenomenon cannot explain our results: In Experiment 3 (Fig. 5), the Rest group showed spontaneous recovery after the first extinction phase $(1 \mathrm{~h}$ and $5 \mathrm{~min}$ after training), but not after the second extinction phase, although this second phase was $1 \mathrm{~h}$ later than the first phase, thus at a time when bees should have been hungrier than before. However, no response recovery was observed in this case, which shows that hunger cannot explain the response recovery observed after the first extinction phase. Lastly, in Experiment 2 (Fig. 4), spontaneous recovery was also obtained $\sim 1 \mathrm{~h}$ after the conditioning trial. However, it appeared when bees received only five extinction trials, but not when bees received 10 extinction trials. As the number of extinction trials is highly unlikely to have an effect on sensitization or on the hunger level of bees, this experiment confirms that responding in the recovery tests depends on the CS-US association, and not on nonassociative phenomena.

\section{Spontaneous Recovery Is Time-Dependent}

The first important result of the present study is that spontaneous recovery is a time-dependent process. First, the time components of acquisition and extinction determine whether spontaneous recovery will occur. Thus, only in the case of massed acquisition and extinction procedures did we obtain significant spontaneous recovery. Second, the duration of the rest period was also crucial for the occurrence of spontaneous recovery: a 1-h rest period was an optimum, shorter or longer periods yielding less recovery. We thus confirm the observation by Bitterman et al. (1983), who found spontaneous recovery in very similar temporal conditions. Traditionally, there have been two main ways of considering extinction: (1) Repeated unrewarded CS presentations produce extinction by undermining the existing CS-US association (e.g., Robbins 1990). (2) Extinction does not wipe out the CS-US associations built in the first place, but gives the CS a second meaning, building a "CS-no US" association. Extinction would thus appear because the CS-no US memory is better retrieved than the initial CS-US association (Rosas and Bouton 1996; Rescorla 1997a,b, 2001). In vertebrates, this second explanation has received substantial experimental support (for review, Myers and Davis 2002). In our work, spontaneous recovery of conditioned responses after a rest period could be interpreted as the indication that extinction in honeybees relies on the building of transient CS-no US associations. However, based on this interpretation, it is difficult to explain the clear time-dependency of the recovery process found in our work. First, the lack of spontaneous recovery found in group Long-long of Experiment 1 would indicate that the CS-no US association was so much stronger in this spaced schedule than in the massed schedule of group Short-short that it inhibited responding for at least $24 \mathrm{~h}$, whereas in the latter case, it inhibited responding during $~ 15 \mathrm{~min}$. This appears unlikely, although in PER conditioning, CS-US associations are known to be stronger when acquisition is provided in a spaced fashion than when it is provided in a massed fashion (Menzel et al. 2001). It could be conceivable that extinction also follows such a rule and that CS-no US associations produced by massed extinction are weaker than those produced by spaced extinction. This interpretation, however, cannot cope with the difference in spontaneous recovery obtained in the Long-short and in the Short-short groups: in both cases, extinction was provided in a massed schedule, but started either $1 \mathrm{~min}$ or $10 \mathrm{~min}$ after conditioning. Although the same level of responses was obtained at the end of extinction (respectively, 27\% [ $n=106]$ and $23 \%[n=126], \chi^{2}=0.58$, NS, $1 \mathrm{df}$ ), spontaneous recovery was strong in the Short-short group but low in the Long-short group. For the reasons stated above, as well as because the explanation that the olfactory memory is updated by extinction is more parsimonious in terms of memory storage, we favor this last interpretation. Indeed, recently, olfactory extinction in Drosophila was shown to be dependent on the same subset of Kenyon cells in the mushroom bodies that were implied in acquisition, suggesting that in this insect extinction updates current memories by inhibiting signaling cascades intracellularly (Schwärzel et al. 2002). In our view, the occurrence of spontaneous recovery is not per se opposed to this idea, if one takes into account the fact that the olfactory memory trace relies on different substrates, i.e., different cellular mechanisms and/or storage in different brain areas. Extinction could well update/erase some of these substrates without inducing the decay of all of them. Spontaneous recovery could then reflect the transition from one memory phase to the next (see our introduction and Fig. 1 for a description of memory phases in bees). Our results can thus be explained based on a simple model of the effect of extinction on memory: the only rule is that extinction weakens the memory phase(s) that is (are) controlling performance to the CS at the time the extinction trials are given (Fig. 6). For instance, a single learning trial, as used in Experiment 1, normally leads to short term memory (STM), which is highly nonassociative (sensitization) and short-lived (Fig. 6A). After 5 to $7 \mathrm{~min}$, consolidation leads to the more specific midterm memory (MTM), which lasts $\sim 1 \mathrm{~d}$. In the case of the Long-long group (Fig. 6B), extinction started 10 min after conditioning, i.e., at the beginning of the MTM phase. According to our model, repeated extinction trials (see vertical arrows) would slowly wipe MTM out. The same would happen in the Long-short group, but MTM would decrease more quickly (in time, not in the number of trials) because trials were given with 1-min intervals (Fig. 6C). As no other memory substrate would control performance afterward, no spontaneous recovery should appear in this case. Our data support this claim, although after a 1-h rest period, bees of the Long-short group showed a certain tendency (although not significant) for recovery. This could only be explained if some kind of early LTM substrate, relatively independent of the memory phase wiped out by extinction, were appearing at this stage (Fig. 6C, "other"). This is not utterly impossible, because a previous study carried out in similar conditions and using pure linalool as the CS found long-term retention after a single CS-US association (Sandoz et al. 1995). In the case of the Short-short group, extinction started very shortly (1 min) after conditioning, at a moment when STM is still active, and MTM only starts consolidating. In this case, extinction would have induced a quicker 
A Performance after single-trial conditioning

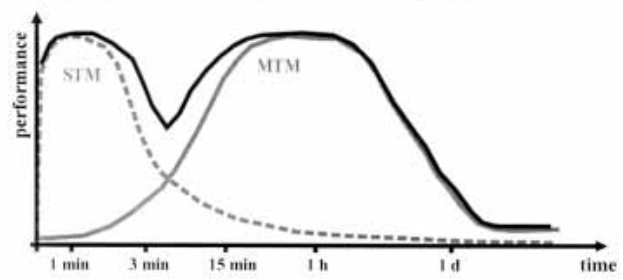

B

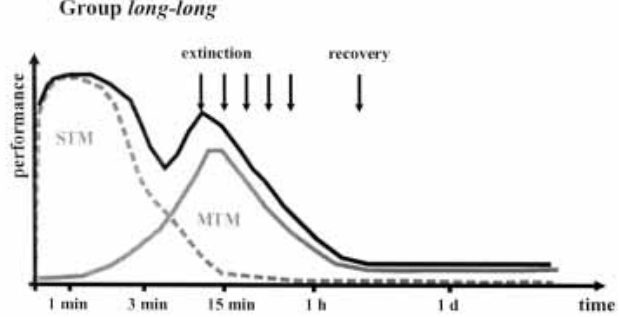

C

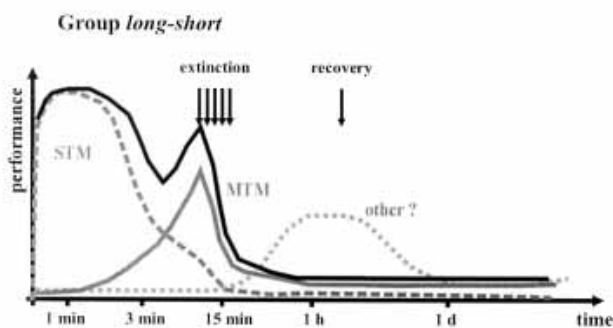

D

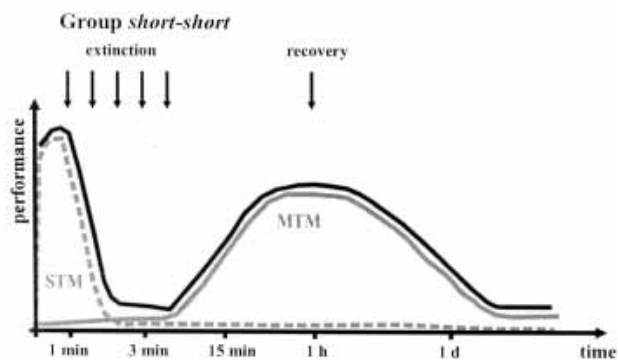

Figure 6 Model of extinction and spontaneous recovery in the honeybee. This model is based on one simple rule, according to which extinction weakens the memory phase(s) that is (are) controlling performance to the CS at the time the extinction trials are given. $(A)$ Time course of PER performance after single-trial conditioning and putative memory phases according to Menzel (2001) —see Figure 1 for details. (B-D) Explanation of the results of Experiment 1 on the basis of our model of extinction and spontaneous recovery. (B) An extinction phase carried out 10 min after conditioning with spaced trials (group Long-long) speeds up the decay of STM, but most importantly erases midterm memory (MTM), reducing performance permanently. No spontaneous recovery is observed. (C) Extinction taking place in a massed fashion 10 min after conditioning (group Long-short) acts in a similar way, but affects MTM more quickly. Our experiments showed a nonsignificant tendency for spontaneous recovery in this group, which could reflect either the fact that extinction could not totally stop the consolidation process and some MTM is present $1 \mathrm{~h}$ after extinction, or that some other (weak) memory form is present. (D) When massed extinction takes place shortly after conditioning (group Short-short), short-term memory (STM) is strongly affected but MTM is only affected in a limited way, leaving the consolidation process somewhat intact, so that some MTM develops and spontaneous recovery can be observed between $15 \mathrm{~min}$ and $1 \mathrm{~d}$ after extinction. decay of STM, without blocking memory consolidation altogether and thus allowing some development of MTM. Spontaneous recovery as found in our work would then be interpreted as the appearance of MTM, with an optimum around $1 \mathrm{~h}$ and a decay already after $24 \mathrm{~h}$ (Fig. 6D). It is important to note that we found spontaneous recovery in these experimental conditions (one conditioning trial and five extinction trials with 1-min ITIs, and 1-h rest period) in five different cases (group Short-short in Experiment 1, conditioning group 1-trial of Experiment 2, extinction group 5-trial of Experiment 2, and groups Rest and Rest and reminder of Experiment 3). In all cases, spontaneous recovery was significant (between 40\% and 69\%) but not total, which means that MTM was not left totally undamaged by extinction. The fact that MTM could survive through extinction carried out shortly after conditioning could seem at odds with the usual claim that the consolidation process is very sensitive to amnestic treatments applied in the first minutes after conditioning (Menzel et al. 1974, 1993; Erber 1975a,b, 1976; Erber et al. 1980). Indeed, electrical brain stimulations given in the first 5 min after conditioning strongly hinder consolidation to MTM. However, such amnestic treatments have a broad effect on the whole brain, whereas extinction probably affects a limited set of cells in the brain. Our data suggest that extinction selectively updates STM, in a way akin to a working memory (Menzel 1999), but that consolidation into MTM, although weakened, is not utterly blocked. This would lead after some time to spontaneous recovery. The present model of extinction and spontaneous recovery is a working model, and should thus be tested in future work.

\section{Spontaneous Recovery Is Trial-Dependent}

We evaluated the effect of multiple trial conditioning and that of extended extinction on spontaneous recovery. First, we found that the number of conditioning trials has a significant and nonmonotonous impact on acquisition and extinction. Increasing the number of conditioning trials over six led to a decrease in conditioned responses (Fig. 3A), an observation that is common in procedures with massed schedules and could be caused by satiation effects (Menzel et al. 2001). We therefore examined extinction only on bees that responded at the first extinction test, discarding individuals that had stopped responding during conditioning. A nonmonotonous effect of the number of conditioning trials on extinction was observed. Although extinction decreased as the number of conditioning trials augmented from one to six, it was again very marked after a nine-trial conditioning procedure (Fig. 3B). This effect is reminiscent of the overlearning extinction effect, a phenomenon found in vertebrates (Ison 1962; Ison and Cook 1964) and already demonstrated on instrumental learning in free-flying bees visiting either colorcued (Couvillon and Bitterman 1980, 1984) or odor-cued feeders (Robacker and Ambrose 1979). In this preparation, Shinoda and Bitterman (1987) showed that satiety cannot account for the overlearning extinction effect, because it also appears in groups of free-flying bees receiving the same total number of food uptakes, but different numbers of rewarded trials with the extinction cue. In the present work, we cannot rule out a role of satiety, although we discarded satiated bees at the beginning of the extinction phase. Future work should control the amount of food applied to confirm the presence of the overlearning extinction effect in PER conditioning.

However, the goal of the present experiment was to evaluate spontaneous recovery after multiple-trial conditioning. Although we found deleterious effects of a high number of conditioning trials on acquisition and extinction, the effect on spontaneous recovery was unambiguous: multiple conditioning trials increased spontaneous recovery from $\sim 50 \%$ after a single trial to $>80 \%$ after three conditioning trials and more (Fig. 3C). This

\section{Learning \& Memory}

www.learnmem.org 
result suggests that spontaneous recovery allowed performance to recover fully after $1 \mathrm{~h}$. Multiple conditioning trials are thought to allow the olfactory memory to enter novel and more permanent stages. First, they lead to a late form of STM (ISTM) that is less susceptible to amnestic treatment (Menzel and Sugawa 1986; Menzel 2001). Then, consolidation leads to a form of very stable MTM (multiple trial MTM) and in the days range, to one or two forms of long-term memory (LTM), one form independent of protein synthesis (eLTM) the other one highly dependent on protein synthesis (ILTM; Menzel 2001; see Introduction). Massed training, as used in Experiment 2, is thought to induce 1-2-d retention based predominantly on eLTM. In the framework of our model, the response decrease observed during extinction would be due to the gradual destruction of ISTM (less rapidly than after a single conditioning trial, except in the case of the nine-trial group, in which overlearning effects may occur; see above). Spontaneous recovery would thus be the appearance of the consolidated and highly specific MTMm phase. This MTMm phase allows higher performance than the single-trial MTM. In Experiment 1, we found that spontaneous recovery was lower after a 24 -h than after a 1 -h rest period, a phenomenon we interpreted as indicative of the natural decay of single-trial MTM. If our interpretation is correct, multiple-trial conditioning should lead to the formation of eLTM, and spontaneous recovery should be high several days after conditioning. This question should be addressed in future research.

In the second part of Experiment 2, we showed that the number of extinction trials was critical for the appearance of spontaneous recovery. After five extinction trials, the level of responses was already very low ( 10\%; Fig. 3A). Adding five extinction trials had no influence on the level of conditioned responses during extinction, but induced much lower spontaneous recovery. This last result confirms data on rats, in which overextinction was also shown to block the occurrence of spontaneous recovery (Rosas and Bouton 1996). In the case of habituation also, stimulation with the habituating stimulus carried out beyond the point when responses are lost induces a reduction of spontaneous recovery (in Drosophila; Engel and Wu 1996). The present results would suggest that prolonged extinction first affected the STM phase and then, being still applied at a moment when consolidation into MTM is ended, provoked the decay of MTM itself. This interpretation is supported by the results of the Long-short group of Experiment 1, in which the extinction phase started during MTM (10 min after conditioning): in this group only a tendency for spontaneous recovery was observed as compared with the Short-short group in which extinction had started earlier (1 min) after conditioning. Our data show that more rewarded trials lead to more spontaneous recovery, whereas more unrewarded trials lead to less recovery. These effects can be explained based on our simple model of extinction and spontaneous recovery.

\section{Spontaneous Recovery Appears Only Once After Single-Trial Conditioning}

Experiment 3 was designed to test our account of extinction, namely, that extinction updates or erases memory. This experiment thus addressed the question whether spontaneous recovery in honeybees is repeatable over time. Bees from the Rest group, which were subjected to four five-trial extinction phases interspersed with 1-h rest periods, showed spontaneous recovery only after the first extinction phase. This confirms the idea that extinction actually causes the decay of memory substrates: As explained above, the first extinction series probably provoked the decay of STM, whereas the second extinction series destroyed the last memory substrate available, i.e., MTM. In a second group, we replaced the rest period by reminder trials, i.e., additional rewarded presentations of the CS. In this case, we found that each reminder trial induced a response increase-as any conditioning trial would do-but that the level of increase weakened throughout the procedure (Fig. 5, middle panel). We do not think that this effect is caused by satiety, because bees received only four rewarded trials in the whole procedure. Rather, we think that during the massed presentation of rewarded and unrewarded trials, performances are controlled by short-term memory (ISTM), like a working memory, which was constantly updated by new information. At any given time, responses actually reflected the content of this working memory. Thus, the impact of reminder trials on responses constantly decreased, showing that bees had integrated rewarded and unrewarded trials throughout training (note that it is a general observation in PER conditioning that the impact of a rewarded trial is much higher than that of an unrewarded trial). The role of such a working memory may be to weigh the influence of massed rewarded and unrewarded experience, before information about the CS is actually stored in longer-term memories. Such phenomena may be especially beneficial while foraging, to adapt to short-lived fluctuations in nectar availability. The Rest and reminder group received both a 1-h rest period and a reminder trial between two extinction phases. These bees, which experienced exactly the same amount (and sequence) of rewarded and unrewarded trials as bees from the Reminder group, but with a different time arrangement, showed a high and constant response level after each reminder trial. Thus, rest periods allowed higher fluctuations of performance. Why is it so? Interestingly, these bees showed spontaneous recovery after every rest period (see responses after T5, T10, and T15, at the beginning of the reminder trial). As before, the first spontaneous recovery can be explained as the decay of STM and consolidation into MTM. The following spontaneous recoveries, however, are the product of reminder trials. We think that each reminder trial induced a double process, and that bees' performances reflect both. First, each reminder trial, like a single conditioning trial, induces a STM process, which extends to the few following extinction trials (as in the Reminder group). During this phase, performance probably reflects the content of such a working memory. High response levels are observed after reminder trials, but also, very rapid extinction occurs. At the same time, as would be the case with any multiple-trial conditioning procedure, reminder trials induce the consolidation leading to the formation (or update) of a highly resistant multiple-trial MTM (Menzel 2001). This phenomenon would be responsible for the increasing level of spontaneous recovery found throughout the experiment (see also the augmentation in spontaneous recovery with increasing conditioning trials observed in Experiment 2). The different extinction series probably affect multiple-trial MTM, but to a much more limited extent than in the case of the more fragile single-trial MTM (Menzel 2001; see Experiment 1 and the group Rest of Experiment 3). This double process appears to be highly reproducible over time.

\section{Prospects in the Study of Insect Extinction and Spontaneous Recovery}

We show that extinction in PER conditioning of bees has opposite long-term effects on responding depending on the time parameters of acquisition and extinction. In some cases (massed extinction), responses recover over time; in other cases (spaced extinction), they do not. Although spontaneous recovery is traditionally interpreted as meaning that extinction does not impair the original CS-US association but produces concurrent inhibitory associations, our results can be explained with the more parsimonious hypothesis that in honeybees, extinction actually 
updates the original CS-US association. Because the olfactory memory depends on at least five sequential and/or parallel memory stages, which may rely on different neural substrates, we hypothesize that depending on acquisition and extinction variables, extinction affects different memory substrates. In particular, we propose that spontaneous recovery in the honeybee is indicative of consolidation from short-term to middle-term memory forms.

In insects, the present study is among the first to deal with the mechanisms of extinction and spontaneous recovery (for another account, see Schwärzel et al. 2002). In contrast, these phenomena are intensively studied in vertebrate models like rabbits (e.g., Napier et al. 1992; Macrae and Kehoe 1999; Medina et al. 2001; Kehoe and White 2002) or rats (e.g., Rosas and Bouton 1996; Rescorla 1996, 1997a, 2001). We expect that future work on insects will highly benefit from the research strategies used in vertebrates. In our view, several findings in these species should be preferentially studied: first, it is a general finding in the rabbit nictitating membrane literature, that even after extinction is extended and no spontaneous recovery is observed anymore, reacquisition of the initial CS-US association is more rapid than observed initially or than in a naive group of animals (Napier et al. 1992; Macrae and Kehoe 1999). This phenomenon, termed "savings," suggests that even after complete behavioral extinction, some residual excitatory strength remains in some brain areas, a fact that has been recently confirmed experimentally in rabbits (Medina et al. 2001). The honeybee PER preparation, because of its strong and rapid acquisition and extinction performance as well as the accessibility of its brain to electro- and optophysiological studies, would be an ideal model for the study of the neurobiological basis of savings in simple nervous systems. A second very important observation in rabbits is that extinction (followed by spontaneous recovery) also appears when the CS is not presented alone, but with a US of lower intensity. This observation led to the hypothesis that extinction with the CS-alone constitutes the zero point on a continuum of US intensity (Kehoe and White 2002). This phenomenon should be explicitly tested in PER extinction in honeybees, in particular because different honeybees display different sucrose responsiveness (Pankiw and Page Jr. 1999), which has an influence on their learning performance (Scheiner et al. 1999, 2001). It would thus be interesting to compare the possible extinction effect of different US decrements on these bees, to test the possibility that US evaluation depends on individual sensitivity for the US. Lastly, "renewal" tests, in which extinguished responses to a CS reappear when the animal is tested in a context different from the extinction context (Bouton and Bolles 1979), can provide important indications concerning the state of the initial CS-US association after extinction. We hope that the present study will prompt new efforts for unraveling the neural basis of extinction in honeybees.

\section{ACKNOWLEDGMENTS}

We are grateful to B. Roger for rearing the bees used in this study. We thank M. Giurfa for helpful comments on the manuscript. The research of J.-C.S. is funded by the French Scientific Research Centre (CNRS).

\section{REFERENCES}

Bitterman, M.E., Menzel, R., Fietz, A., and Schäfer, S. 1983. Classical conditioning of proboscis extension in honeybees. J. Comp. Psychol. 97: 107-119.

Bouton, M.E. and Bolles, R.C. 1979. Contextual control of the extinction of conditioned fear. Learn. Motiv. 10: 455-466.

Brandes, C., Frisch, B., and Menzel, R. 1988. Time-course of memory formation differs in honey bee lines selected for good and poor learning. Anim. Behav. 36: 981-985.

Couvillon, P.A. and Bitterman, M.E. 1980. Some phenomena of associative learning in honeybees. J. Comp. Physiol. Psychol. 94: $878-885$.

1984. The overlearning-extinction effect and successive negative contrast in honeybees. J. Comp. Psychol. 98: 100-109.

Engel, J.E. and Wu, C.F. 1996. Altered habituation of an identified escape circuit in Drosophila memory mutants. J. Neurosci. 16: 3486-3499.

Erber, J. 1975a. The dynamics of learning in the honey bee (Apis mellifica carnica). I. The time dependence of the choice reaction. $J$. Comp. Physiol. 99: 231-242.

. 1975b. The dynamics of learning in the honey bee (Apis mellifica carnica). II. Principles of information processing. J. Comp. Physiol. 99: 243-255.

. 1976. Retrograde amnesia in honeybees (Apis mellifera carnica). J. Comp. Physiol. Psychol. 90: 41-46.

Erber, J., Masuhr, T., and Menzel, R. 1980. Localization of short-term memory in the brain of the bee, Apis mellifera. Physiol. Entomol. 5: $343-358$.

Friedrich, A., Thomas, U., and Müller, U. 2004. Learning at different satiation levels reveals parallel functions for the cAMP-protein kinase A cascade in formation of long-term memory. J. Neurosci.

24: $4460-4468$.

Grünbaum, L. and Müller, U. 1998. Induction of a specific olfactory memory leads to a long-lasting activation of protein kinase $\mathrm{C}$ in the antennal lobe of the honeybee. J. Neurosci. 18: 4384-4392.

Hammer, M., Braun, G., and Mauelshagen, J. 1994. Food-induced arousal and nonassociative learning in honeybees: Dependence of sensitization on the application site and duration of food stimulation. Behav. Neural Biol. 62: 210-223.

Heisenberg, M. 2003. Mushroom body memoir: From maps to models. Nat. Rev. Neurosci. 4: 266-275.

Ison, J.R. 1962. Experimental extinction as a function of number of reinforcements. J. Exp. Psychol. 64: 314-317.

Ison, J.R. and Cook, P.E. 1964. Extinction performance as a function of incentive magnitude and number of acquisition trials. Psychon. Sci. 1: $245-246$.

Izquierdo, L.A., Barros, D.M., Vianna, M.R.M., Coitinho, A., Silva, T.D.E., Choi, H., Moletta, B., Medina, J.H., and Izquierdo, I. 2002. Molecular pharmacological dissection of short- and long-term memory. Cell. Mol. Neurobiol. 22: 269-287.

Kehoe, E.J. and White, N.E. 2002. Extinction revisited: Similarities between extinction and reductions in US intensity in classical conditioning of the rabbit's nictitating membrane response. Anim. Learn. Behav. 30: 96-111.

Kuwabara, M. 1957. Bildung des bedingten Reflexes von Pavlovs Typus bei der Honigbiene, Apis mellifica. J. Fac. Hokkaido Univ. Ser. VI Zool. 13: $458-464$.

Macrae, M. and Kehoe, E.J. 1999. Savings after extinction in conditioning of the rabbit's nictitating membrane response. Psychobiology 27: 85-94.

Medina, J.F., Garcia, K.S., and Mauk, M.D. 2001. A mechanism for savings in the cerebellum. J. Neurosci. 21: 4081-4089.

Menzel, R. 1990. Learning, memory and "cognition" in honey bees. In Neurobiology of comparative cognition (eds. R.P. Kesner and D.S. Olten), pp. 237-292. Erlbaum, Hillsdale, NJ. . 1999. Memory dynamics in the honeybee. J. Comp. Physiol. A 185: $323-340$.

. 2001. Searching for the memory trace in a mini-brain, the honeybee. Learn. Mem. 8: 53-62.

Menzel, R. and Sugawa, M. 1986. Time course of short-term memory depends on associative events. Naturwissenschaften 73: 564-565.

Menzel, R., Erber, J., and Masuhr, T. 1974. Learning and memory in the honeybee. In Experimental analysis of insect behaviour (ed. L.B. Browne), pp. 195-217. Springer Verlag, Berlin.

Menzel, R., Hammer, M., Braun, G., Mauelshagen, J., and Sugawa, M. 1991. Neurobiology of learning and memory in honeybees. In The behaviour and physiology of bees (eds. J.L. Goodman and R.C. Fischer), pp. 323-353. CAB International, Wallingford, UK.

Menzel, R., Greggers, U., and Hammer, M. 1993. Functional organization of appetitive learning and memory in a generalist pollinator, the honey bee. In Insect learning (ed. A.C. Lewis), pp. 79-125. Chapman Hall, New York.

Menzel, R., Manz, G., Menzel, R.M., and Greggers, U. 2001. Massed and spaced learning in honeybees: The role of CS, US, the inter-trial interval and the test interval. Learn. Mem. 8: 198-208.

Müller, U. 2000. Prolonged activation of cAMP-dependent protein kinase during conditioning induces long-term memory in honeybees. Neuron 27: 159-168.

Myers, K.M. and Davis, M. 2002. Behavioral and neural analysis of extinction. Neuron 36: 567-584.

Napier, R.M., Macrae, M., and Kehoe, E.J. 1992. Rapid reacquisition in conditioning of the rabbit's nictitating membrane response. J. Exp. Psychol. Anim. Behav. Processes 18: 182-192. 
Pankiw, T. and Page Jr., R.E. 1999. The effect of genotype, age, sex, and caste on response thresholds to sucrose and foraging behavior of honey bees (Apis mellifera L.). J. Comp. Physiol. A 185: 207-213.

Pavlov, I. 1927. Conditioned reflexes. Dover Publications, New York.

Pham-Delègue, M.H., De Jong, R., and Masson, C. 1990. Effet de l'âge sur la réponse conditionnée d'extension du proboscis chez l'abeille domestique. C. R. Acad. Sci. Ser. III 310: 527-532.

Rescorla, R.A. 1996. Spontaneous recovery after training with multiple outcomes. Anim. Learn. Behav. 24: 11-18.

. 1997a. Spontaneous recovery of instrumental discriminative responding. Anim. Learn. Behav. 25: 485-497.

1997b. Spontaneous recovery after Pavlovian conditioning with multiple outcomes. Anim. Learn. Behav. 25: 99-107.

. 2001. Retraining of extinguished Pavlovian stimuli. J. Exp. Psychol. 27: 115-124.

Robacker, D.C. and Ambrose, J.T. 1979. Effects of number of reinforcements and interference on visual and olfactory learning modalities of the honey bee (hymnoptera: apidae). Ann. Entomol. Soc. Am. 72: 775-780.

Robbins, S.J. 1990. Mechanisms underlying spontaneous recovery in autoshaping. J. Exp. Psychol. Anim. Behav. Processes 16: 235-249.

Rosas, J.M. and Bouton, M.E. 1996. Spontaneous recovery after extinction of a conditioned taste aversion. Anim. Learn. Behav. 24: 341-348.

Rose, S.P.R. and Stewart, M.G. 1999. Cellular correlates of stages of memory formation in the chick following passive avoidance training. Behav. Brain Res. 98: 237-243.

Sandoz, J.C., Roger, B., and Pham-Delègue, M.H. 1995. Olfactory learning and memory in the honeybee: Comparison of different classical conditioning procedures of the proboscis extension response. C. R. Acad. Sci. Ser. III 318: 749-755.

Sandoz, J.C., Hammer, M., and Menzel, R. 2002. Side-specificity of olfactory learning in the honeybee: US input side. Learn. Mem. 9: 337-348.

Scheiner, R., Erber, J., and Page Jr., R.E. 1999. Tactile learning and the individual evaluation of the reward in honey bees (Apis mellifera L.). J. Comp. Physiol. A 185: 1-10.

Scheiner, R., Page Jr., R.E., and Erber, J. 2001. Responsiveness to sucrose affects tactile and olfactory learning in preforaging honey bees of two genetic strains. Behav. Brain Res. 120: 67-73.

Schwärzel, M., Heisenberg, M., and Zars, T. 2002. Extinction antagonizes olfactory memory at the subcellular level. Neuron 35: 951-960.

Seeley, T.D. 1982. Adaptive significance of the age polyethism schedule in honeybee colonies. Behav. Ecol. Sociobiol. 11: 287-293.

Shinoda, A. and Bitterman, M.E. 1987. Analysis of overlearning-extinction effect in honeybees. Anim. Learn. Behav. 15: $93-96$.

Takeda, K. 1961. Classical conditioned response in the honey bee. J. Insect Physiol. 6: 168-179.

Vareschi, E. 1971. Duftunterscheidung bei der Honigbiene-Einzelzell-Ableitungen und Verhaltensreaktionen. $Z$. Vergleich. Physiol. 75: 143-173.

Received May 7, 2004; accepted in revised form August 4, 2004. 


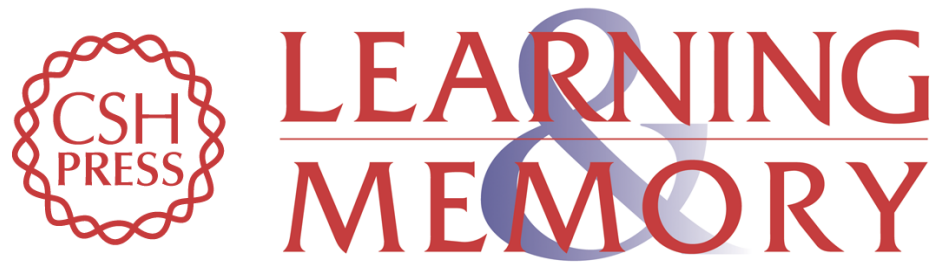

\section{Spontaneous Recovery After Extinction of the Conditioned Proboscis Extension Response in the Honeybee}

Jean-Christophe Sandoz and Minh-Hà Pham-Delègue

Learn. Mem. 2004, 11:

Access the most recent version at doi:10.1101//m.81504

References This article cites 43 articles, 7 of which can be accessed free at:

http://learnmem.cshlp.org/content/11/5/586.full.html\#ref-list-1

License

Email Alerting Receive free email alerts when new articles cite this article - sign up in the box at the Service top right corner of the article or click here. 